\title{
СИСТЕМА ЗОВНІШНЬОГО ПІДСИЛЕННЯ ЗАЛІЗОБЕТОННИХ ЗГИНАЛЬНИХ ЕЛЕМЕНТІВ І МОДЕЛЮВАННЯ ЇЇ РОБОТИ
}

\section{THE SYSTEM OF EXTERNAL REINFORCEMENT OF REINFORCED CONCRETE BENDING ELEMENTS AND MODELINGT HER WORK}

\begin{abstract}
Чеканович М. Г., к. т. н, проф., ORCID ID: 0000-0002-9110-4109, Романенко С. М., ст. викладач, ORCID ID: 0000-0002-0443-3896 Андрісвська Я. П. асистент, ORCID ID: 0000-0003-3052-2515 (Херсонський державний аграрний університет)
\end{abstract}

Chekanovich M.G., candidate of technical science, professor, Romanenko S.M. senior lecturer, Andrievska Ya.P. assistant

Підсилення залізобетонних елементів, таких як балки та плити широко застосовуються у будівельній практиці. В останні роки обсяги застосування підсилення високі, що обумовлено значним зростанням питомої ваги реконструкції в будівництві. Будівельні конструкції потребують підсилення, яке забезпечить достатню роботоздатність та надійність в умовах нормальної експлуатації. Приведені результати аналізу поведінки під навантаженням згинальних залізобетонних елементів підсилених саморегульованою затяжкою і звичайною балкою та розглянуто математичну модель розрахунку системи підсилення.

Strengthening of reinforced concrete elements such as beams and slabs is widely used in construction practice. In recent years, reinforcement application has increased due to a significant increase in the share of reconstruction in construction. This is the result of changes in stress, physical deterioration of existing buildings because of their poor maintenance and other factors, which leads to bearing capacity loss; that is why structures need to be strengthened to ensure sufficient performance under normal maintenance and reliability.

The variety of methods mentioned can be divided into 3 groups: strengthening with a change in the constructive and design scheme of a reinforced concrete member; strengthening without changing the work pattern of structures by building up their cross-sections with additional external reinforcement; strengthening by prestressing beams with horizontal ties.

Tie bars can be of three types - horizontal, sprengel and combined ones. When applying prestressed tie bars, the strengthened elements change their original constructive scheme because they turn into a combined system. Due to this, conventional bending elements are compressed noncentrally, and at their supports additional bending moments are created, which in turn influence the initial span moments. In this case, in all the variants of reinforcing beams with 
tie bars there are still significant reserves of increasing their carrying capacity.

The results of analysis behavior under the load of bended reinforced concrete elements reinforced by a self-regulating tightening with a conventional beam are given and the mathematical model of the amplification system calculation is considered.

Ключові слова: затяжка, переріз, напруження, деформації, міцність tendons, cross-section, stress, strain, strength.

Вступ. Підсилення залізобетонних елементів, таких як балки та плити (ребристі, багатопустотні та ін.) широко застосовуються у будівельній практиці. В останні роки обсяги застосування підсилення зросли, що обумовлено значним зростанням питомої ваги реконструкції в будівництві. Це відбувається внаслідок зміни навантажень, фізичного зносу існуючих будівель і споруд, внаслідок незадовільної їх експлуатації та іншого, що призводить до втрат несучої здатності, тому будівельні конструкції потребують підсилення, яке забезпечить достатню роботоздатність та надійність в умовах нормальної експлуатації. [1].

Аналіз останніх досліджень. Відомі доволі різноманітні методи підсилення залізобетонних елементів, що згинаються [2-13]. Науковою та конструкторсько-технологічною основою застосування таких підсилених конструкцій у будівництві є дослідження вітчизняних та зарубіжних авторів: Є.М. Бабіча, А.М. Бамбури, Б.Г. Демчини, 3.Я. Бліхарський, Г.I. Бердичівського, В.О. Воблих, А.А. Гвоздєва, А.Б. Голишева, Є.О. Гриневича, О.Л. Шагіна, Ф.С. Замалієвим, М.Ю. Ізбаша, В.Г. Кваші, Ф.С. Клименка, Ф. Леонгардта, Є.О. Лучковського, В.В. Михайлова, Н.М. Онуфрієва, С.Ф. Пічугіна, Е.Г. Ратца, Л.I. Стороженка, Е. Фрейсіне, Цзян Де, Richard W. Plavidal, Thomas Keller та ін. Розроблені методи можна розділити на 3 великі групи: підсилення зі зміною конструктивної та розрахункової схеми залізобетонного елемента; підсилення без зміни схем роботи конструкцій нарощуванням їх перерізів, додатковим зовнішнім армуванням; підсилення балки горизонтальними затяжками.

Постановка мети і задач досліджень. Система підсилення має на меті відновлення i збільшення несучої здатності залізобетонних згинаних елементів, зменшення їх деформативності та вигинів.

Методика досліджень. Натяжна конструкція підсилення має вигляд дзеркально симетрично розташованої затяжки в приопорних зонах балки 3 нахилом поздовжньої осі балки. Поперечна арматура балки, закріплена одним кінцем на верхній грані балки ближче до ії середини з обмеженням зміщення до середини, а іншим кінцем на нижній грані балки ближче до ії опор з обмеженням зміщення до опор і з можливістю поздовжнього розтягу верхньої грані балки і обтиску нижньої ії грані та поперечного стиску приопорних зон. У якості зовнішньої арматури використовувалась арматура Ø8 мм класу А400С, необхідно визначити переміщення вузлів 1, 2, 3 стержневої системи, зображеної на рисунку 1, площа поперечного перерізу 
стержнів дорівнює $A_{s}=0,503 \mathrm{~cm}^{2}$. Довжини стержнів: $111=6 \mathrm{~cm} ; 121=6 \mathrm{~cm}$; $131=6,26 \mathrm{~cm} ; 112=18 \mathrm{~cm} ; 122=15,5 \mathrm{~cm} ; 132=14 \mathrm{~cm}$.

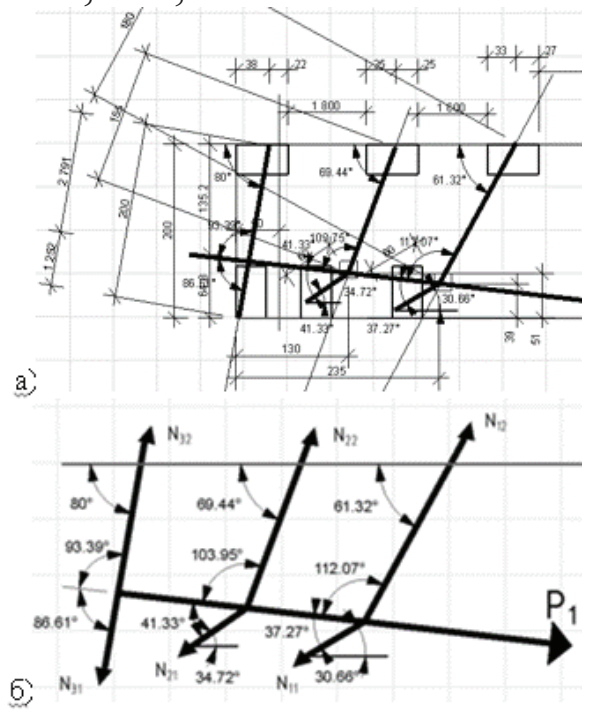

Рис. 1. Схема стержневої системи:

а) розміри; б) направлення дії сил

Виходячи з умов рівноваги вузлів 1, 2, 3 під дією навантажень $P_{1}, P_{2} P_{3}$ відповідно і зусиль в стержнях $N_{11}, N_{12}, N_{21}, N_{22}, N_{31}, N_{32}$, які необхідно знайти, було побудовано силовий трикутник для кожного вузла. За теоремою синусів знаходимо:

$$
\begin{aligned}
& N=\frac{P \cdot \sin \alpha^{0}}{\sin \beta^{0}} \approx x P \\
& N_{11}=\frac{P_{1} \cdot \sin 112^{0}}{\sin 61.32^{0}} \approx 1,0568 \cdot P_{1} \quad N_{12}=\frac{P_{1} \cdot \sin 37.27^{0}}{\sin 61.32^{0}} \approx 0,6902 \cdot P_{1} \\
& N_{21}=\frac{P_{2} \cdot \sin 105^{0}}{\sin 69,44^{0}} \approx 1,0316 \cdot P_{2} \quad N_{22}=\frac{P_{2} \cdot \sin 41.33^{0}}{\sin 69.44^{0}} \approx 0,7053 \cdot P_{2} \\
& N_{31}=\frac{P_{3} \cdot \sin 93,39^{\circ}}{\sin 80^{\circ}} \approx 1,0136 \cdot P_{3} \quad N_{32}=\frac{P_{3} \cdot \sin 86.61^{\circ}}{\sin 80^{\circ}} \approx 1.0136 \cdot P_{3}
\end{aligned}
$$

Абсолютні видовження стержнів визначаються залежністю:

$$
\Delta l_{i 1}=\frac{N_{i 1} \cdot l_{i 1}}{E_{c m} \cdot A_{s 1}} \quad \Delta l_{i 2}=\frac{N_{i 2} \cdot l_{i 2}}{E_{c m} \cdot A_{s 2}}
$$

Якщо $A_{s 1}=A_{s 2}=0,503 \mathrm{~cm}^{2}$ - площа поперечного перерізу стержнів, то при заданому значенні $\mathrm{P}$ знаходимо величини абсолютних видовжень кожного стержня.

$$
\begin{aligned}
& \Delta l_{11}=6,892 \cdot 10^{-3} \quad \Delta l_{12}=13,584 \cdot 10^{-3} \quad \Delta l_{21}=6,767 \cdot 10^{-3} \\
& \Delta l_{22}=11,953 \cdot 10^{-3} \quad \Delta l_{31}=6,937 \cdot 10^{-3} \quad \Delta l_{32}=15,516 \cdot 10^{-3}
\end{aligned}
$$

Так як значення абсолютних видовжень стержнів малі величини по відношенню до довжини стержнів, то для знаходження положення шарнірів 
1, 2, 3 після деформації (точки 1', 2', 3') можна відкласти на продовженні кожного стержня величину його видовження і провести із отриманої точки перпендикуляр у напрямку стержня. Отримана таким чином геометрична побудова $\epsilon$ діаграмою переміщень. Абсолютне видовження будь-якого стержня заданої стержневої системи дорівнює алгебраїчній сумі проекцій горизонтального $\Delta x$ і вертикального $\Delta y$ переміщень шарніра за напрямком стержня, дивись рисунок 2.

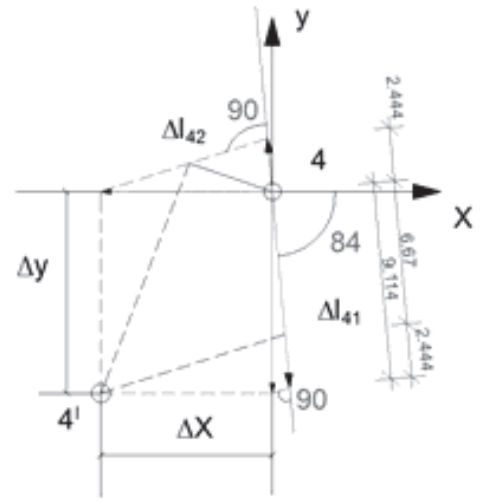

Рис. 2 - Діаграма переміщень 3-го вузла з визначенням проекцій $\Delta x_{\mathrm{i}} \Delta y$ переміщень шарніра на напрямок 1-го стержня

Виразимо абсолютне видовження $\Delta l_{31}$ та $\Delta l_{32}$ через проекції $\Delta x$ та $\Delta y$ :

$$
\Delta l_{31}=\Delta y \cdot \sin 84^{\circ}-\Delta x \cdot \cos 84^{0} ; \Delta l_{32}=\Delta x \cdot \cos 19^{\circ}-\Delta y \cdot \sin 19^{0}
$$

Маємо систему рівнянь 3 двома невідомими. Звідси знаходимо:

$$
\Delta x=7,42 \cdot 10^{-3}(\text { cм }) \quad \Delta y=9,93 \cdot 10^{-3}(\text { см })
$$

Переміщення $\Delta x$ та $\Delta y$ для 1-го, 2-го та 3-го вузлів знаходимо аналогічно.

Отже, маємо:

для 1-го вузла: $\Delta x=4,06 \cdot 10^{-3} \mathrm{cM}, \Delta y=6,37 \cdot 10^{-3} \mathrm{cM}$;

для 2-го вузла: $\Delta x=5,31 \cdot 10^{-3} c M, \Delta y=7,15 \cdot 10^{-3} c M$;

для 3-го вузла: $\Delta x=7,42 \cdot 10^{-3} c M, \Delta y=9,93 \cdot 10^{-3} c \mathcal{c}$.

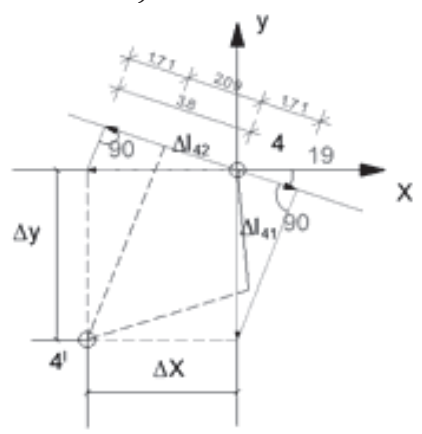

Рис. 3 - Діаграма переміщень 3-го вузла з визначенням проекцій $\Delta x_{\text {i }} \Delta y$ переміщень шарніра на напрямок 2-го стержня 
Знаходимо для кожного вузла загальну величину переміщення $\Delta$ за залежністю:

$$
\Delta=\sqrt{\Delta x^{2}+\Delta y^{2}}
$$

Щоб визначити як розподіляється сила Р між вузлами 1, 2, 3 застосуємо гіпотезу, згідно якої перепад сил між поперечною арматурою обернено пропорційний видовженню вздовж напряму дії сили $\mathrm{P}$ при одній і тій же величині Р.

$$
k_{1}=\frac{1}{\Delta_{1}}=\frac{1}{0,007}=142,85 \quad k_{3}=\frac{1}{\Delta_{4}}=\frac{1}{0,012}=83,33 \quad k_{2}=\frac{1}{\Delta_{2}}=\frac{1}{0,0085}=117,64
$$

Коефіцієнт пропорційності розподілення сили Р буде дорівнювати:

$$
\begin{gathered}
n_{i}=\frac{k_{i}}{k_{1}+k_{2}+k_{3}} \\
k_{1}+k_{2}+k_{3}=142,85+117,64+83,33=343,82 \\
n_{1}=\frac{142,85}{343.82}=0,415 ; \quad n_{2}=\frac{117,64}{343.82}=0,343 ; \quad n_{3}=\frac{83,33}{343.82}=0,242
\end{gathered}
$$

Тут $n_{1}+n_{2}+n_{3}=1$

Результати досліджень. Для підсиленої балки розраховано значення сили Р по 3 стадіям навантаження, результати занесені до таблиці 1:

Таблица 1

Розподілимо прийняті сили Р між вузлами 1-3 з урахуванням визначених коефіцієнтів та знаходимо сили N. Результати представлені у таблиці 2,3:

Таблица 2

Зведена таблиця сил Р у кН з урахуванням визначених коефіцієнтів

\begin{tabular}{|c|c|c|c|}
\hline Сила Р & $P_{1}$ & $P_{2}$ & $P_{3}$ \\
\hline 0,774 & 0,774 & 0,452 & 0,5085 \\
\hline 5,6388 & 5,6388 & 3,298 & 3,704 \\
\hline 18,377 & 18,377 & 10,750 & 12,073 \\
\hline
\end{tabular}


Таблиця 3

Зведена таблиця сил $\mathrm{N}$ у кН з урахуванням визначених коефіцієнтів

\begin{tabular}{|c|c|c|c|c|c|c|}
\hline Сила Р & $N_{11}$ & $N_{21}$ & $N_{21}$ & $N_{12}$ & $N_{22}$ & $N_{22}$ \\
\hline 0,774 & 0,817 & 0,466 & 0,515 & 0,534 & 0,318 & 0,515 \\
\hline 5,6388 & 5,959 & 3,402 & 3,821 & 3,891 & 2,326 & 3,754 \\
\hline 18,377 & 19,42 & 11,08 & 12,237 & 12,683 & 7,581 & 12,237 \\
\hline
\end{tabular}

Після проведених розрахунків епюру моментів від системи підсилення та прикладеного зовнішнього навантаженням у третинах балки, показана на рисунку 4.

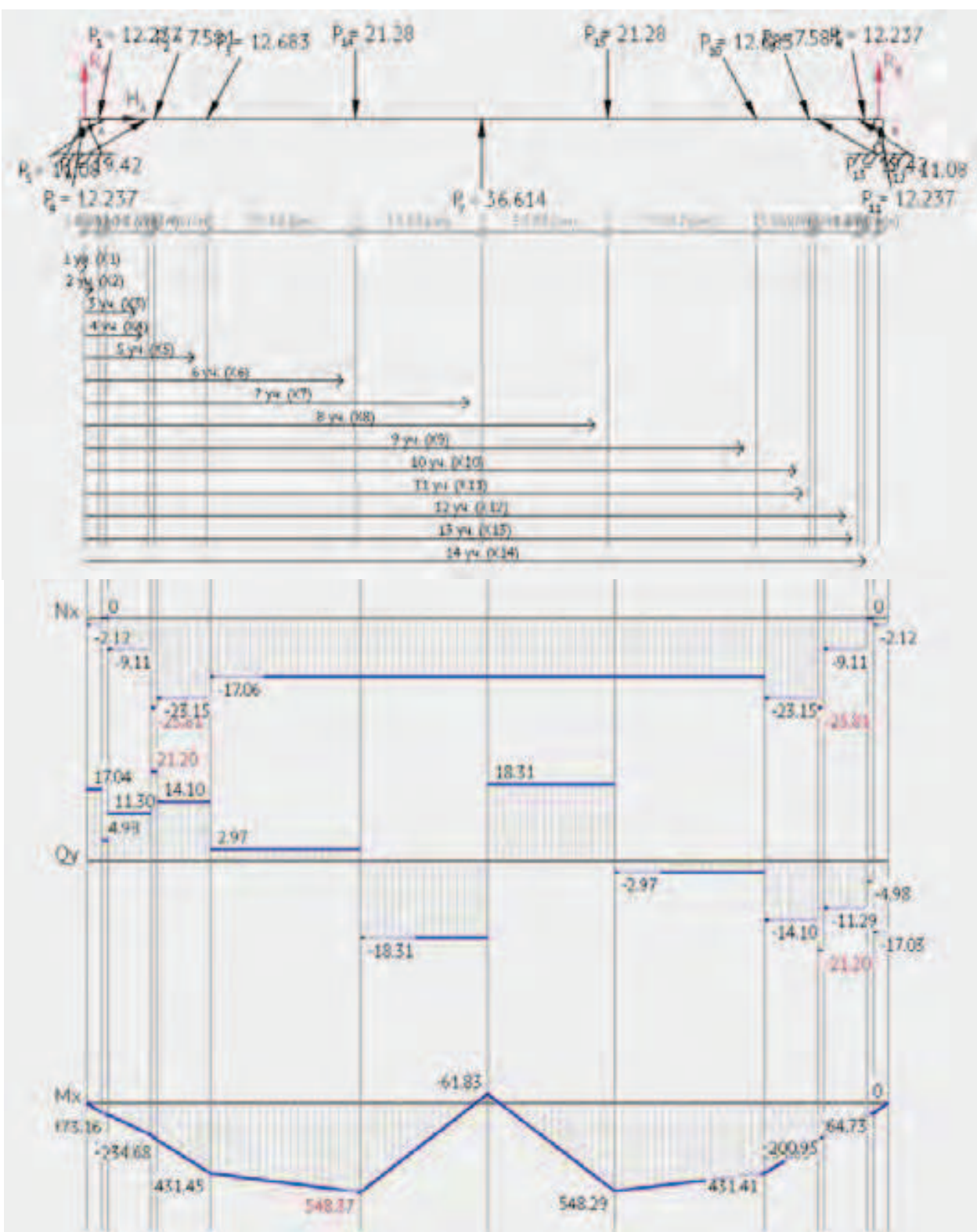

Рис. 4 . Епюра від дії системи підсилення та прикладеного зовнішнього навантаження

Висновки. Система підсилення дозволяє відновити і збільшити несучу здатність згинаних елементів та підвищити їх жорсткість. Підсилення 
поздовжньо-поперечною зовнішньою системою згинаних елементів $\epsilon$ перспективним і ефективним заходом у будівництві.

1. Барашиков А.Я., Малышев А.Н. Оценка технического состояния строительных конструкций, зданий и сооружений.-К.: НМЦ Держнаглядохоронпраці, 1998.-232 c.

2. Бабич В. С., Поляновська О. С., Борейчук Л. М. Аналіз розрахунку деформацій залізобетонних згинальних елементів за різними методиками./ Бабич В. Є., Поляновська О. С., Борейчук Л. М. // наукових праць «Ресурсоекономні матеріали, конструкції, будівлі та споруди». випуск 32 - Рівне, Національний університет водного господарства та природокористування, 2016 - с. 121-129. ISSN 2218-1873

3. Бліхарський 3.Я., Пелешко І.Д., Балук I.М. Формування розрахункових схем i визначення напружено деформованого стану стрижневих металевих конструкцій у процесі реконструкції й підсилення/ Бліхарський 3.Я., Пелешко І.Д., Балук І.М.// Збірник металеві конструкції, Том 19, Вип. 1, 2013, с. 37-47.

4. Стороженко Л.І, Тимошенко В.М. Стелезалізобетонні структурні плити для пролітних будо мостів / Стороженко Л.І, Тимошенко В.М.// Збірник наукових праць «Дороги і мости», вип. 9-Київ, 2008. - 254-260с.

5. Шагин, А.Л. Локальное предварительное напряжение железобетонных и сталежелезобетонных конструкций / А.Л. Шагин // Юбилейные научные чтения по проблемам теории железобетона. Наука, технологии, производство: сб.тр. - М.: МИКХиС,2009. - С. 107 - 116.

6. Голышев А.Б., Ткаченко И.Н. Проектирование усилений несущих железобетонных конструкций производственных зданий и сооружений.-К.:Логос, 2001.- $172 \mathrm{c}$.

7. Онуфриев Н.М. Усиление железобетонных конструкций промышленных зданий и сооружений. - Ленинград, 1965. - 342 с.

8. Чеканович М.Г., Романенко С.М., Андрієвська Я.П. An effective structure strengthening reinforced concrete baems./ Чеканович М.Г., Романенко С.М., Андрієвська Я.П.// Збірник наукових праць Academic Journal. Series: Industrial Machine Building, Civil Engineering. - Issue 1 (48)’ 2017 - Полтава, Полтавський національний технічний університет імені Юрія Кондратюка, 2017 - с. 81-90. ISSN 2409-9074, 2017.

9. Клименко С.В. Технічна експлуатація та реконструкція будівель і споруд: навчальний посібник/ С.В. Клименко. - К.: Центр навчальної літератури, 2004. - С. 171

10. Patent No.: CN 102936965 A Jiang De «Method for strengthening reinforced concrete beam through distributed external prestressing cables» 2013.02.20

11. Patent No.: US 7,748,180 B1 Richard W. Plavidal «Joist stiffening system» Jul. 6,2010

12. Patent No.: US 7,056,463 B2 Toshiaki Ohta, Fukuoka (JP) Japan Scince and Technology Agency, Saltama (JP) «Method of manufacturing prestressed Concrete» Jun. 6, 2006

13. Патент України № 99090 U, МПК Е04С3/20 Регульовано напружена балка Чекановича/ a2014 14006; опубл25.05.2015 бюл. №10

1. Barashikov A.Ya., Malyshev A.N. Ocenka tekhnicheskogo sostoyaniya stroitel'nyh konstrukcij, zdanij i sooruzhenij.-K.: NMC Derzhnaglyadohoronpraci, 1998.-232 s.

2. Babich V. E., Polyanovs'ka O. E., Borejchuk L. M. Analiz rozrahunku deformacij zalizobetonnih zginal'nih elementiv za riznimi metodikami./ Babich V. C., Polyanovs'ka O. C., Borejchuk L. M. // naukovih prac' «Resursoekonomni materiali, konstrukciï, budivli ta 
sporudi». vipusk 32 - Rivne, Nacional'nij universitet vodnogo gospodarstva ta prirodokoristuvannya, 2016 - s. 121-129. ISSN 2218-1873

3. Blihars'kij Z.Ya., Peleshko I.D., Baluk I.M. Formuvannya rozrahunkovih skhem i viznachennya napruzheno deformovanogo stanu strizhnevih metalevih konstrukcij u procesi rekonstrukciï j pidsilennya/ Blihars'kij Z.YA., Peleshko I.D., Baluk I.M.// Zbirnik metalevi konstrukciï, Tom 19, Vip. 1, 2013, s. 37-47.

4. Storozhenko L.I, Timoshenko V.M. Stelezalizobetonni strukturni pliti dlya prolitnih budo mostiv / Storozhenko L.I, Timoshenko V.M.// Zbirnik naukovih prac' «Dorogi i mosti», vip. 9-Kiïv, 2008. - 254-260s.

5. SHagin, A.L. Lokal'noe predvaritel'noe napryazhenie zhelezobetonnyh i stalezhelezobetonnyh konstrukcij / A.L. SHagin // YUbilejnye nauchnye chteniya po problemam teorii zhelezobetona. Nauka, tekhnologii, proizvodstvo: sb.tr. - M.: MIKKHiS,2009. - S. 107 - 116.

6. Golyshev A.B., Tkachenko I.N. Proektirovanie usilenij nesushchih zhelezobetonnyh konstrukcij proizvodstvennyh zdanij i sooruzhenij.-K.:Logos, 2001.- 172s.

7. Onufriev N.M. Usilenie zhelezobetonnyh konstrukcij promyshlennyh zdanij i sooruzhenij. - Leningrad, 1965. - 342 s.

8. CHekanovich M.G., Romanenko S.M., Andrievs'ka YA.P. An effective structure strengthening reinforced concrete baems./ CHekanovich M.G., Romanenko S.M., Andrievs'ka YA.P.// Zbirnik naukovih prac' Academic Journal. Series: Industrial Machine Building, Civil Engineering. - Issue 1 (48)' 2017 - Poltava, Poltavs'kij nacional'nij tekhnichnij universitet imeni YUriya Kondratyuka, 2017 - s. 81-90. ISSN 2409-9074, 2017.

9. Klimenko E.V. Tekhnichna ekspluataciya ta rekonstrukciya budivel' i sporud: navchal'nij posibnik/ C.V. Klimenko. - K.: Centr navchal'noï literaturi, 2004. - S. 171

10. Patent No.: CN 102936965 A Jiang De «Method for strengthening reinforced concrete beam through distributed external prestressing cables» 2013.02.20

11. Patent No.: US 7,748,180 B1 Richard W. Plavidal «Joist stiffening system» Jul. 6, 2010

12. Patent No.: US $7,056,463$ B2 Toshiaki Ohta, Fukuoka (JP) Japan Scince and Technology Agency, Saltama (JP) «Method of manufacturing prestressed Concrete» Jun. 6, 2006

13. Patent Ukraïni № 99090 U, MPK E04S3/20 Regul'ovano napruzhena balka Chekanovicha/ a2014 14006; opub125.05.2015 byul. №10 